\title{
Electrocardiographic Changes in Amitriptyline Poisoning
}

\author{
R. J. BARNES,* M.D., M.R.C.P.ED.; S. M. KONG, $\dagger$ M.B., B.S. ; RAYMOND W. Y. WU, $†$ M.B., B.S.
}

Brit. med. 7., 1968, 3, 222-223

\begin{abstract}
Cummary : In imipramine and amitriptyline poisoning the electrocardiographic abnormalities comprise arrhythmias, widening of the QRS complex, and marked changes in the S-T segment. These features were found to be of value in the differential diagnosis of unknown poisoning. The unusual configuration of $q R$ with raised $S-T$ segment in V1, simulating myocardial infarction, was seen in one of our patients and has been noted in four cases reported by other workers.
\end{abstract}

\section{Introduction}

Imipramine and amitriptyline are pharmacologically similar compounds, and are classed as antidepressive drugs with anticholinergic effects (Laurence, 1966). The electrocardiogram of imipramine poisoning has been amply documented (Arneson, 1961 ; Connelly and Venables, 1961 ; Alajem and Albagli, 1962 ; Garrison and Moffitt, 1962 ; Giles, 1963 ; Jacobziner and Raybin, 1963 ; Prout, Young, and Goddard, 1965 ; Braun, Brodehl, Fichsel, and Kallfelz, 1965 ; Rasmussen, 1965 ; Ramsay, 1967), but that of amitriptyline poisoning has been less frequently reported (Fendrick, 1962; Sunshine and Yaffe, 1963 ; Lloyd, Hart, and Torode, 1967). The following is an endeavour to assess the presently recognized electrocardiographic changes, and reports two cases of amitriptyline poisoning.

\section{Case 1}

The patient, a girl aged 17, was found comatose in her home. There was no definite history or evidence that any drugs had been taken, but she had been beaten with a stick by her father for not wanting to continue schooling. There was no trauma to the head. An unsteady gait was noted shortly before the patient lapsed into unconsciousness. After admission to the ward she developed status epilepticus, which did not respond to intramuscular paraldehyde and sodium phenobarbitone. Intravenous thiopentone and tracheal intubation with positive-pressure respiration on a Beaver apparatus had to be instituted. The blood pressure was around $70 / 50$. Her pupils were moderately dilated and reactive to light. The tendon reflexes were brisk and plantar reflexes extensor. Examination of the gastric lavage revealed the presence of large amounts of amitriptyline. She gradually regained consciousness over a period of three days, and admitted to having taken a handful of her mother's Tryptizol tablets.

Lead I of the electrocardiogram taken on admission (Fig. 1) shows the beginning of supraventricular tachycardia in the last three complexes of the tracing. This was preceded by nodal rhythm and two ventricular ectopic beats. Supraventricular tachycardia with a slurred descending stroke of $S$, followed by a markedly depressed S-T segment, is seen in leads II, V4, V5, and V6. The width of QRS is best seen in V3 and measures $0.12 \mathrm{sec}$. The corrected Q-T (Q-Tc) interval was 0.48 sec., and the tracing in $\mathrm{V} 1$ and $\mathrm{V} 2$ showed $\mathrm{qR}$ with reciprocal $\mathrm{S}-\mathrm{T}$ elevation. Two and a half hours later the electrocardiogram (Fig. 2) showed sinus rhythm, a QRS of $0.10 \mathrm{sec}$., and a Q-Tc interval of $0.45 \mathrm{sec}$. Leads V1 and $V 2$ showed $R$ with raised $S-T$ segment. The record on discharge was essentially normal (QRS $0.08 \mathrm{sec}$., Q-Tc interval 0.41 sec.)

\footnotetext{
* Specialist (Medicine), Queen Elizabeth Hospital, Hong Kong Government.

† Medical Officer, Queen Elizabeth Hospital, Hong Kong Government.
}

\section{Case 2}

A woman aged 46 was found unconscious in her home and was brought to the casualty department. The duration of unconsciousness was not known, as she was discovered by her neighbours. Generalized convulsions occurred in the casualty department, and $8 \mathrm{ml}$. of paraldehyde was given intramuscularly before she was admitted to the ward. No further history was obtained.

Her condition on admission was poor. Pupils were normal in size and reacted sluggishly to light. All the limbs were flaccid and tendon reflexes were absent. Plantar reflexes were also absent. An electrocardiogram (Fig. 3) taken soon after the physical examination showed the bizarre picture highly suggestive of amitriptyline poisoning. The arrhythmia was abolished by $1 \mathrm{mg}$. of neostigmine intramuscularly. Her respiratory movements were satisfactory, and positive-pressure respiration, though held in readiness, was not utilized. Gastric lavage was performed, and subsequent analysis of the contents confirmed the presence of amitriptyline. Her blood pressure, pulse rate, and respiration remained satisfactory, though frequent twitching of muscles was observed. On the third day of admission generalized convulsions again developed, and electrocardiogram showed similar abnormal
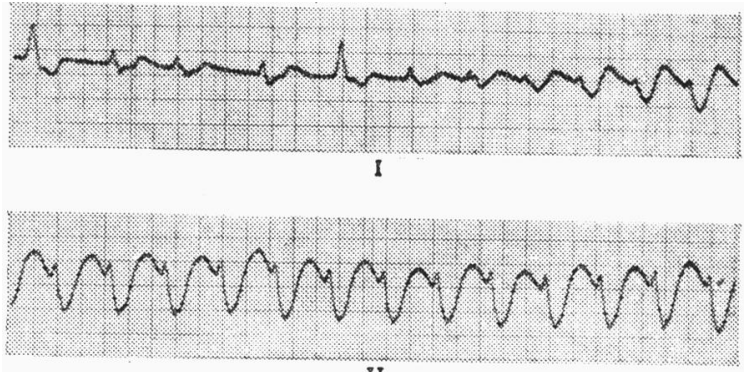

II

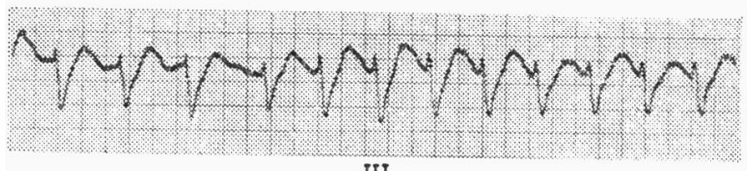

III
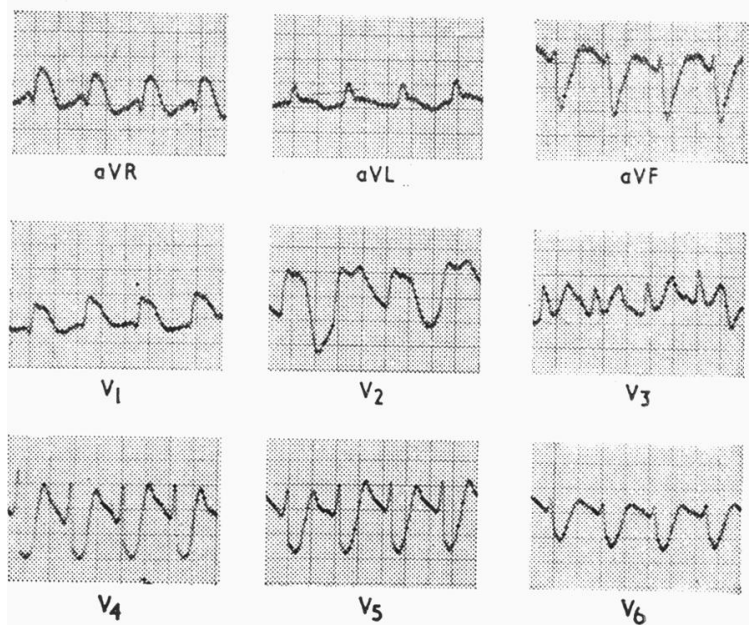

Fig. 1.-Electrocardiogram of Case 1 on admission. 
rhythm and QRS complexes as on admission. Neostigmine $1 \mathrm{mg}$. intramuscularly was again effective in controlling the arrhythmia, but unfortunately the patient died the next day.
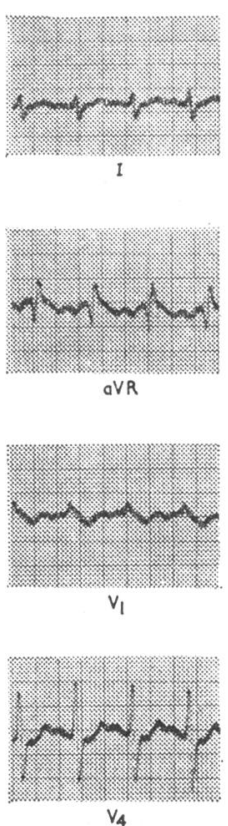

$\mathrm{V}_{4}$

FIG. 2.-Electrocardiogram of Case 1 two and a half hours after the first recording.
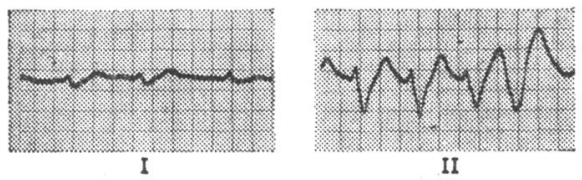

II
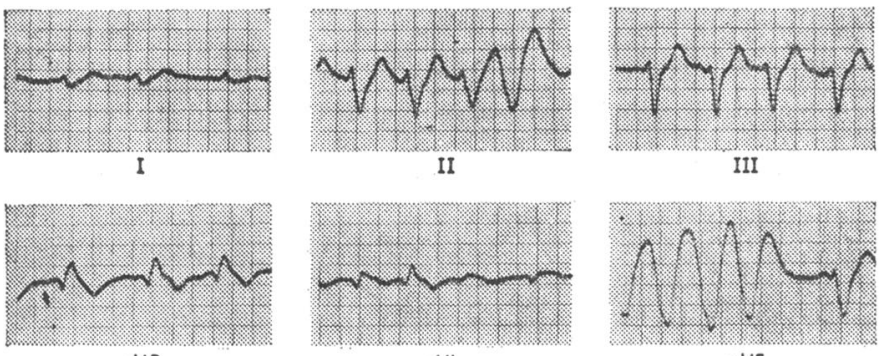

aVR

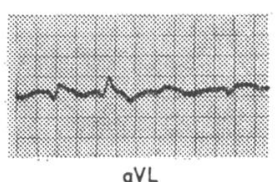

QVL

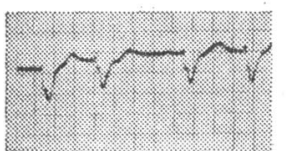

$v_{1}$
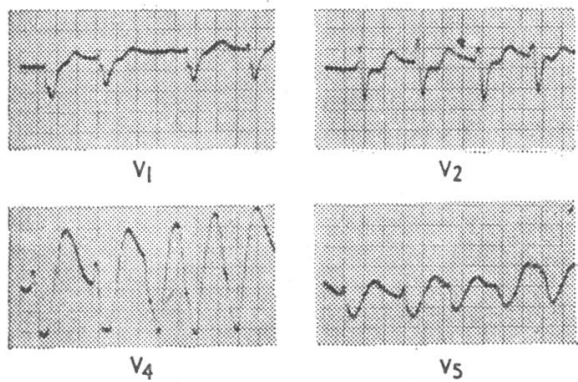

$\mathrm{V}_{2}$

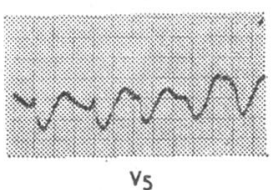

$v_{5}$

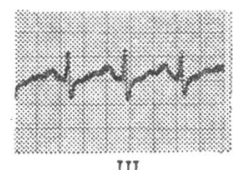

III
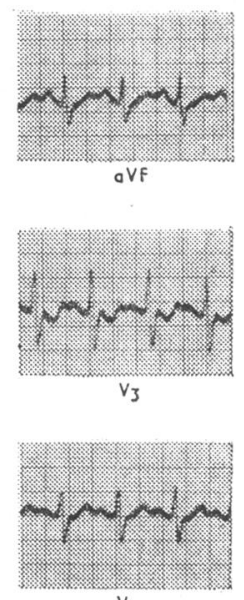

$v_{6}$
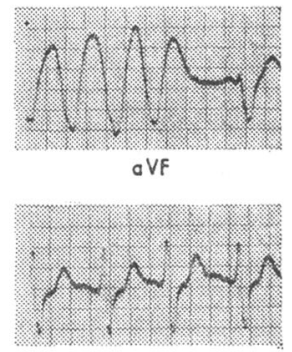

$\mathrm{V}_{3}$

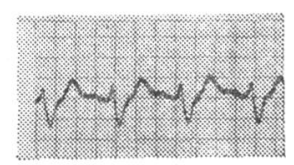

$\mathrm{V}_{6}$

FIG. 3.-Electrocardiogram of Case 2 on admission.

\section{Discussion}

In view of the known effect of imipramine and amitriptyline on the myocardium it should be useful to review the reported electrocardiographic changes seen in poisonings with this class of drugs. Unfortunately not all the reported cases showed tracings of the electrocardiograms (Connelly and Venables, 1961; Sunshine and Yaffe, 1963; Prout et al., 1965; Rasmussen, 1965), but the authors have described varying arrhythmias, such as atrioventricular block, atrioventricular dissociation, right bundle-branch block, supraventricular tachycardia, ventricular flutter, and multiple ectopic beats. Wide QRS complexes with marked S-T shifts were described by Connelly and Venables (1961) and by Prout et al. (1965).

Inspection of the available electrocardiographic tracings in papers by Arneson (1961), Alajem and Albagli (1962), Garrison and Moffitt (1962), Giles (1963), Braun et al. (1965), Lloyd et al. (1967), and Ramsay (1967) shows the striking features of varying arrhythmias and/or widening of the QRS complex with S-T shifts. The widened QRS complex is often associated with marked shift of the S-T segment, which gives the impression of extensive intraventricular block or ventricular tachycardia. This pattern is well seen in leads II, V4, V5, and V6 of Case 1. A qR was present in V1 and V2, and was followed by S-T elevation, giving rise to a pattern resembling that of myocardial infarction in this case (Fig. 1) as well as in cases reported by Alajem and Albagli (1962), Giles (1963), and Braun et al. (1963).

Case 2 was admitted about one month after Case 1, and it was possible to alert the biochemist of the possibility of amitriptyline poisoning on the findings of the electrocardiogram.

The electrocardiographic changes in imipramine and amitriptyline appear to be very similar, and have been shown to be of value in distinguishing antidepressive drug poisoning from other drug poisoning. It must be conceded, however, that the less severe cases of imipramine and amitriptyline poisoning may show no significant changes in the electrocardiogram apart from sinus tachycardia and $T$-wave flattening (Lancaster and Foster, 1959; Steel, O'Duffy, and Brown, 1957).

\section{REFERENCES}

Alajem, N., and Albagli, C. (1962). Amer. F. Dis. Child., 103, 702. Arneson G. A. (1961). Amer. F. Psychiat. 117, 934.

Braun, L., Brodehl, J., Fichsel, H., and Kallfelz, C. (1965). Med. Klin., 60, 1737 .

Connelly, J. F. and Venables, A. W. (1961). Med. 7. Aust., 1, 108.

Fendrick, G. M. (1962). New Engl. भ. Med., 267, 1031.

Garrison, H. F., and Moffitt, E. M. (1962). F. Amer. med. Ass., 179, 456. Giles, H. McC.' (1963). Brit. med. F., 2, 844.

Jacobziner, H., and Raybin, H. W. (1963). N.Y. St. F. Med., 63, 1394. Lancaster, N. P., and Foster, A. R. (1959). Brit. med. F., 2, 1458.

Laurence, D. R.' (1966). Clinical Pharmacology, 3rd. ed." London.

Lloyd, T. W., Hast, D. R., and Torode, S. A. (1967). Lancet, 2, 716.

Prout, B. J., Young, J. and Goddard, P. (1965). Brit. med. 7., 1, 972

Ramsay, I. D. (1967). Lancet, 2, 1308.

Ramsay, I. D. (1967). Lancet, 2, 1308.

Rasmussen, J. O'Duffy, J., and Brown, S. S. (1967). Brit. med. 7., 3, 663.

Sunshine, P., and Yaffe, S. J. (1963). Amer. F. Dis. Child., 106, 501. 